\title{
How to tackle a possible Creutzfeldt-Jakob disease necropsy
}

\author{
J E Bell, J W Ironside
}

\section{Introduction}

The clinical diagnosis of Creutzfeldt-Jakob disease is based on a history of rapidly progressive dementia, presence of myoclonic movements, and a characteristic electroencephalogram. ${ }^{1}$ However, clinical features are not always clearcut, and diagnostic overlap with other forms of dementia, including Alzheimer's disease, remains a problem in many cases. ${ }^{2}$ Some patients have atypical dementing illnesses which defy clinical categorisation; post mortem examination is necessary to achieve correct diagnosis in all cases of atypical dementia and suspected Creutzfeldt-Jakob disease. Most patients with classic Creutzfeldt-Jakob disease display at least some spongiform change in brain tissue. ${ }^{3}$ This well recognised neuropathological feature is strongly supportive of a diagnosis of Creutzfeldt-Jakob disease, but is not pathognomonic because it is also found occasionally in cases of diffuse Lewy body disease and even in Alzheimer's disease. ${ }^{4}$ However, other histological features, such as neurofibrillary tangles, senile plaques, and Lewy bodies assist in clarifying the final diagnosis. Creutzfeldt-Jakob disease can be transmitted to animals or man following inoculation or transplantation of infected tissue..$^{5-7}$ Research has shown that Creutzfeldt-Jakob disease and the related Gerstmann-Straussler syndrome are characterised by the presence of prion protein $(\operatorname{PrP})$ which constitutes a significant part, if not the whole, of the infective agent. ${ }^{8}$ Recent progress in molecular biology has identified abnormalities in the $\operatorname{PrP}$ gene in some cases of familial Creutzfeldt-Jakob disease and in other cases of familial dementia with no characteristic pathology. ${ }^{9}$ These findings represent a challenge to the current classification of dementia and require urgent investigation. This places a very high priority on performing necropsy in cases suspected of having Creutzfeldt-Jakob disease.

Creutzfeldt-Jakob disease resembles spongiform encephalopathy in animals and the epidemic of bovine spongiform encephalopathy (BSE) has led to anxiety that the incidence of Creutzfeldt-Jakob disease will rise. ${ }^{10}$ Because of this concern, the Department of Health has funded the setting up of a nationwide surveillance project to monitor the incidence of Creutzfeldt-Jakob disease, and this study is based in Edinburgh. ${ }^{11}$ The clinical surveillance is supervised by $\operatorname{Dr} R$ Will to whom all patients with a likely diagnosis of Creutzfeldt-Jakob disease should be notified. A very important part of the study is to obtain the brain for histological examination in as high a proportion of CreutzfeldtJakob disease cases as possible. Although guidelines for Creutzfeldt-Jakob disease necropsies have been published before, ${ }^{12-14}$ the safety protocols contained therein need to be updated in the light of current knowledge. The Creutzfeldt-Jakob disease agent is a category 2 pathogen which presents special hazards in that it survives formalin fixation.

Some Creutzfeldt-Jakob disease cases are cared for in neurology units, and a neuropathologist with access to a specialised "high risk" mortuary may be asked to do the necropsy. In these circumstances, provided with dedicated instruments, autoclavable power saw, and full protective clothing, an extended necropsy, including removal of the spinal cord, can be undertaken. However, some cases occur in hospitals with no ready access to such facilities, and in these cases a more limited necropsy has to be performed. This article has been prepared in response to numerous requests for practical guidance by general histopathologists who have been asked to perform a necropsy in a case of possible or probable Creutzfeldt-Jakob disease. It is possible to remove the brain in a way which avoids contamination of staff and environment in all mortuaries with standard facilities. The method is outlined below and illustrated in figs 1-8.

\section{Method}

THE NECROPSY

Attendance at the necropsy is limited to the pathologist and a maximum of two mortuary staff. All staff should wear disposable suits, masks, visors and two pairs of rubber gloves. Details of additional protective equipment are given in the Addendum.

The body is placed supine on the table with the neck supported on a block so that 
Figs 1-7 Necropsy sequence for safe and "contained" brain removal in a case of suspected Creutzfeldt-Fakob disease.

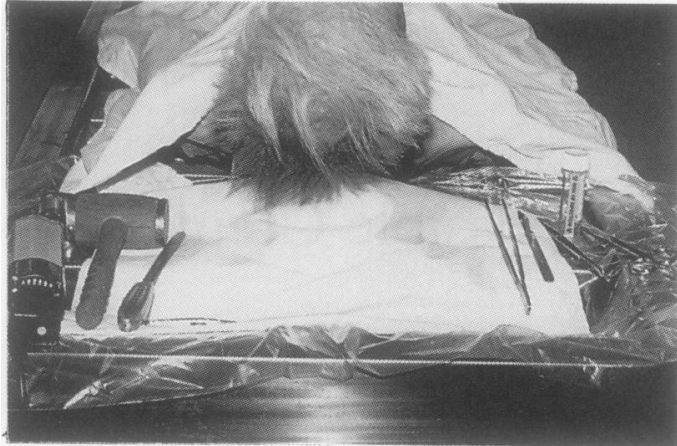

Figure 1 An absorbent pad and collected instruments are arranged before necropsy begins.

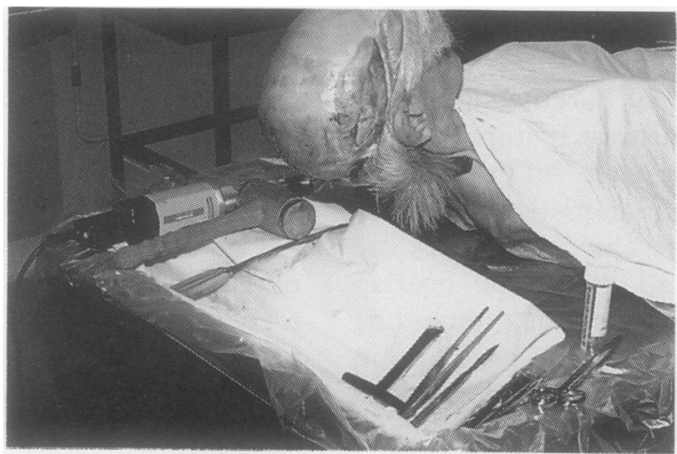

Figure 2 The scalp is reflected in the usual way.

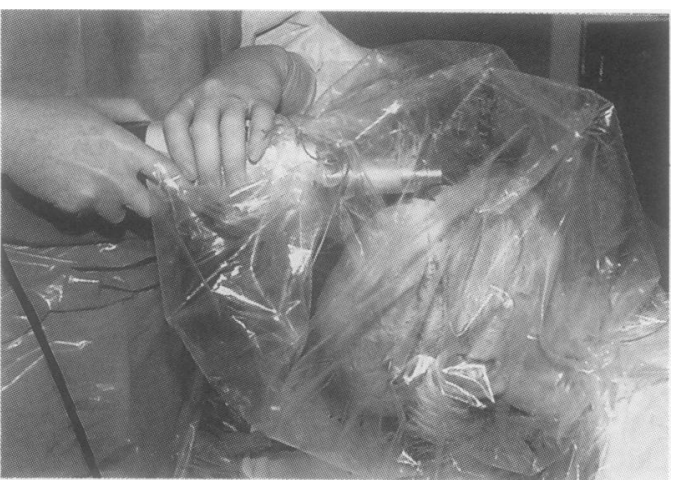

Figure3 The skull vault is partially drilled by an electric necropsy saw within a polythene bag. the head does not project beyond the end of the table. The table beneath the head is covered with impermeable material such as a sheet of polythene which is then covered by an absorbent pad (fig 1). The necessary tools which are to be used in the necropsy are gathered on the absorbent pad. These include scalpel, T-chisel, electric saw, mallet, dura stripper, forceps and scissors (fig 1).

The scalp is incised and reflected in the usual way and the skull is prepared for the application of the saw (fig 2).

A large, clear, polythene bag is placed over the head of the cadaver and secured with string around the neck so that quite a quantity of air separates the inside of the bag from the surface of the skull (fig 3). The electric saw is then introduced through a hole in the top of the bag which is sealed around the neck of the saw as far back as possible, but not enclosing the air vents further back on the shaft. This arrangement should allow enough movement of the saw blade within the bag so that it can be applied easily at any point around the circumference of the skull. Keeping the bag clear of the blade when it is switched on, the skull cap is drilled in the usual way. All the bone dust collects at the base of the bag. When this stage has been completed, the necropsy saw is removed through the hole at the top of the bag and this hole is resealed. The necropsy saw is laid down on the absorbent pad (as are all other instruments before and after use).

With the polythene bag still in place over the head, the skull cap is removed using $T$ chisel, mallet, and dura stripper introduced through small incisions on the superior surface of the bag (figs 4 and 5). The skull cap falls to the bottom of the bag.

The polythene bag may now be removed, handling with care because it contains bone dust and blood (fig 5). The skull cap is retained on the absorbent pad (fig 6).

The dura is incised and reflected from the surface of the brain. At this stage, a specimen of cerebrospinal fluid may be aspirated from

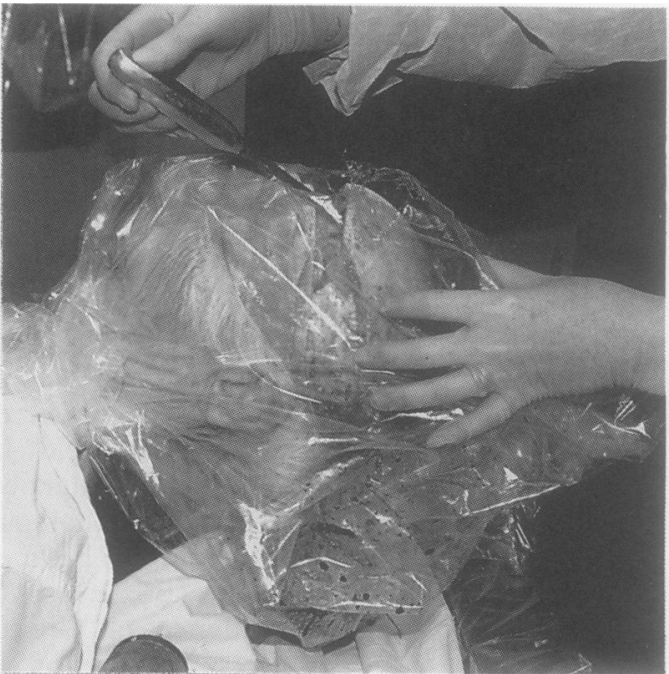

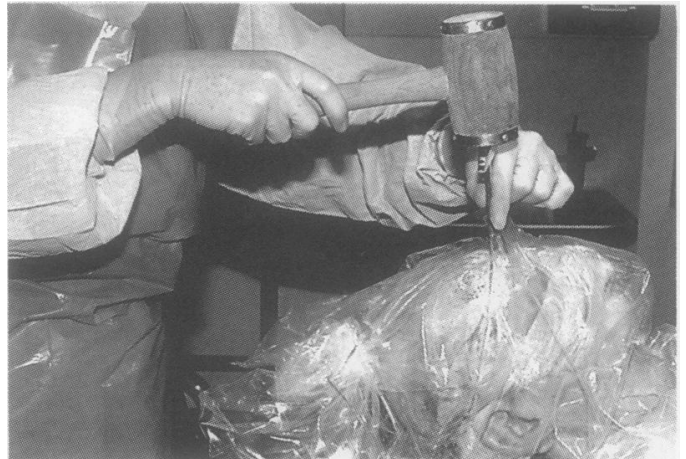

Figures 4 and 5 The skull cap is loosened and removed within the polythene bag. 

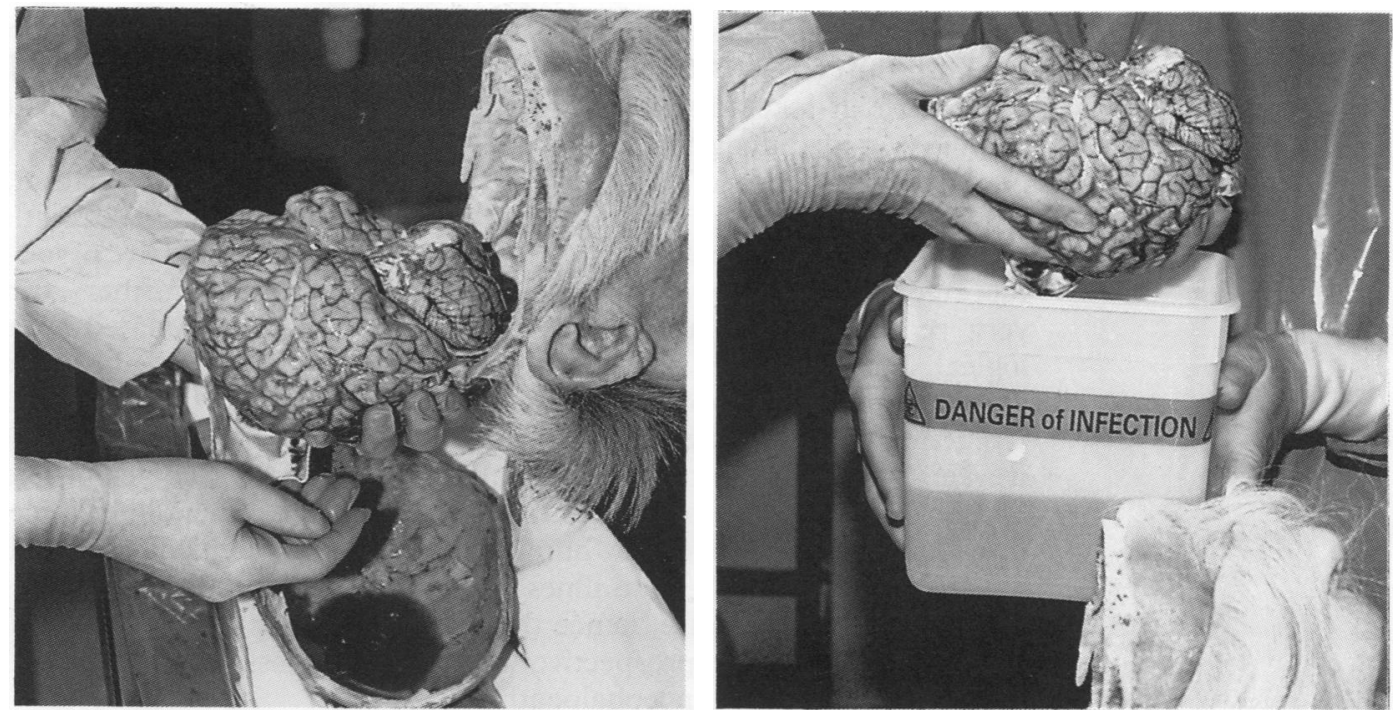

Figures 6 and 7 After removal of the polythene bag, the brain is detached and placed in a pre-weighed container of formalin.

the third ventricle and tissue for freezing removed from the frontal lobes and from the cerebellum. These should be placed directly in universal containers labelled with warning of hazard and with patient identification. The brain is subsequently removed in the usual way (fig 6) and placed directly into a preweighed container of $10 \%$ formalin which is similarly labelled (fig 7). The container is handled by a clean assistant who brings it to the necropsy table. The container is sealed and weighed again to determine brain weight. Finally, the pituitary gland is removed and fixed in formalin. Phenol should not be added to the formalin as it has been shown to be ineffective in decontamination. ${ }^{15}$

The body is reconstituted in the usual way by packing the skull cap with cotton wool and replacing it before the scalp is sutured.

If desired, the body cavities may be opened and the organs examined as usual, with tissue sampling for histology. Care should be taken, as before, to avoid contamination of the mortuary environment. The organs should be examined on the necropsy table, or possibly in situ in the body cavities. Large absorbent pads with impermeable backing should be in place under the cadaver.

Great care should be taken to avoid cuts and needle stick injuries, particularly from contact with sharp bony edges, and during sewing up.

POST-NECROPSY PROCEDURE

All instruments apart from the necropsy saw are gathered from the absorbent pad into a large stainless steel dish, wrapped, and steam autoclaved at $136^{\circ} \mathrm{C}$ for 1 hour, after which they may be cleaned by routine methods. The necropsy saw is cleaned by wiping repeatedly with $2 \mathrm{~N}$ sodium hydroxide solution. The absorbent pad and impermeable table cover, together with all disposable clothing, are double bagged for incineration. After removal of the body, the table and necropsy suite are cleaned in the usual way. No special precautions are needed because the surfaces have not been contaminated. However, if contamination is suspected, a solution of $2 \mathrm{~N}$ sodium hydroxide should be used for cleaning surfaces by repeated wetting over 1 hour. The recommended dilution of chlorine solution for decontamination $(20000 \mathrm{ppm}$ of free chlorine $)^{16}$ is highly unpleasant to use and corrosive to steel.

The fixed brain can be stored safely in $10 \%$ formalin, in a box and an outer polythene bag, pending histological study. Samples for freezing should be double bagged and stored at $-70^{\circ} \mathrm{C}$. Notification of the necropsy to the Edinburgh Creutzfeldt-Jakob disease Surveillance Unit (see below) will be followed by collection of the specimens and, in due course, return of a full pathology report.

Any tissue blocks from non-central nervous system tissues may be decontaminated for routine microtomy by immersion for 1 hour in $96 \%$ formic acid, after formalin fixation and before processing. ${ }^{17}$

\section{Discussion}

This method of containment for removal of infective necropsy brain tissue within a polythene bag has been recommended in the past for AIDS cases $^{18}$ where specialist pathology suites were not available. It is equally suitable for cases of suspected Creutzfeldt-Jakob disease and is quite straightforward to undertake. It is hoped that use of this method would help to alleviate anxiety among pathology staff when confronted with cases of Creutzfeldt-Jakob disease and would allow the necropsy examination to proceed. Although spread of this disease is not thought to occur through contact with blood or bone, and the main risk remains inoculation, ${ }^{16}$ it is clearly wise to limit contamination of staff and mortuary, which is why we recommend use of a polythene bag during skull removal. The relative risk of potential infectivity is lower in non central nervous system tissues apart perhaps from spleen and lymphoid tissue, ${ }^{19}$ and examination of the whole body 
may be thought desirable at necropsy, to establish the cause of death.

Creutzfeldt-Jakob disease is a rare disorder; previous epidemiological studies have suggested an incidence of around $0.5-1 /$ million population worldwide. Although a few cases of Creutzfeldt-Jakob disease have been reported in laboratory technical staff, ${ }^{20}$ and very recently in a pathologist, ${ }^{21}$ epidemiological studies have repeatedly failed to demonstrate an excess incidence of Creutzfeldt-Jakob disease in health care workers and post mortem room staff. In the United Kingdom the theoretical risk of transmission of the BSE agent to humans via the foodchain might result in an illness similar to Creutzfeldt-Jakob disease, hence the need for a longterm national prospective survey of human spongiform encephalopathies. The need for necropsy examination of (at least) the brain in suspected cases is of paramount importance for diagnostic verification and research, particularly in relation to cell pathology, molecular biology, and transmissibility. We hope that the work of the National Creutzfeldt-Jakob disease Surveillance Unit will continue to be supported by histopathologists, neuropathologists, and their mortuary and laboratory technical staff throughout the United Kingdom, on whose cooperation this project depends. Without this sort of help the study will not be successful and any possible hazards of BSE to human health will remain undetected.

The need for histological studies in suspected cases of Creutzfeldt-Jakob disease may pose further difficulties in relation to tissue handling in routine laboratories. The agent is classified as a category 2 pathogen, for which appropriate containment facilities are required. Furthermore, special precautions are required in relation to tissue sectioning, the disposal of contaminated laboratory fluids, and decontamination of equipment and work surfaces. These restrictions make it impracti-

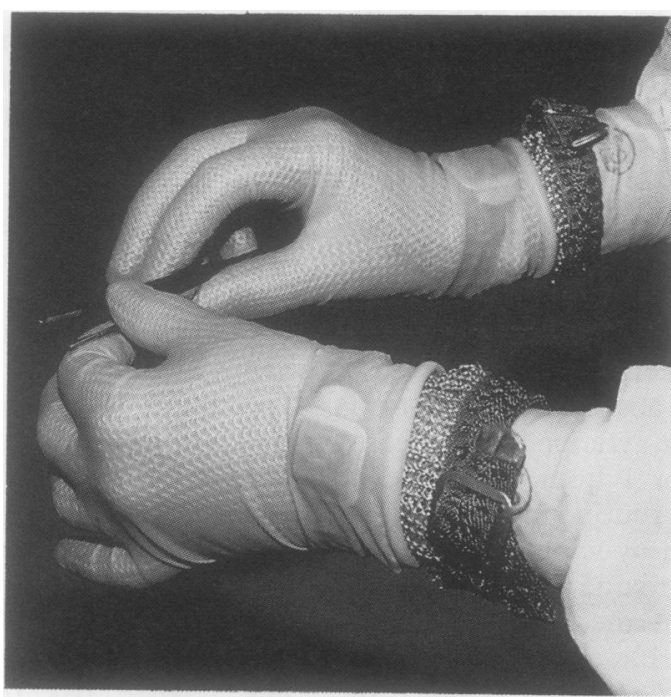

Figure 8 Additional hand protection is afforded by the use of chain mail gloves worn between two pairs of rubber gloves. These protect against cuts and grazes but not needlestick injuries. cable for many laboratories to process and section Creutzfeldt-Jakob disease tissue, in which case the National Creutzfeldt-Jakob disease Surveillance Unit will arrange the collection, examination, and reporting of such material on request. Small non-central nervous system tissue blocks which do not require further trimming may be easily decontaminated by immersion in formic acid and processed routinely.

For further details of the National Creutzfeldt-Jakob disease Surveillance Project and for copies of necropsy protocols and tissue handling, please contact Miss J Mackenzie (the Unit Coordinator) at Creutzfeldt-Jakob disease Surveillance Unit, Old Pharmacy Building, Western General Hospital. Tel: 0313322117.

\section{Addendum}

\section{NOTE ON PROTECTIVE CLOTHING AND} EQUIPMENT

Disposable clothing is now readily available in necropsy suites. As an extra precaution against cutting injury, a pair of chain mail gloves can be worn between double rubber gloves (fig 8). These are surprisingly flexible and convenient to use but do not prevent needle stick injuries and they are expensive (Suppliers-Arco, PO Box 21, Waverley St., Hull HU1 2SJ. Tel: 0482 27678).

Because the polythene bag restricts the amount of aerosol and reduces the risk of splash during necropsy, the need for eye and respiratory tract protection is minimised. However, the use of a visor is recommended during any neuropathological necropsy. If further safeguard is desired, a ventilated visor should be considered. These are light and comfortable to wear, although bulky, and provide a filtered stream of air down over the face, (Suppliers-Pureflo Safety Ltd., Moat House, Wheathampstead, St. Albans, Herts. AL4 8QT. Tel: 0582 834242).

A necropsy saw, with detachable autoclavable head, is now available which is entirely suitable for all necropsy needs and is particularly suited for use in possible Creutzfeldt-Jakob disease cases. (SuppliersMercian Surgical Supply Co. Ltd., 10 Wolverhampton Road, Warley, Birmingham B68 OLH. Tel: 021429 1133). A different model, the Medezine Swordfish (SuppliersAlfred Cox (Surgical) Ltd, Edward Road, Coulsdon, Surrey, CR5 2XA. Tel: 081668 2131) has an advantage in that it can be attached to an extra filtration unit, thus reducing the amount of aerosol. However, the Swordfish is not autoclavable and, being of bulky construction, is less convenient when removing spinal cords.

We are grateful to colleagues from all over the United Kingdom who have gone to a great deal of trouble to notify us of cases, remove brains, or arrange for cases to be moved to the nearest suitable necropsy facility. We thank Mr L Brett for expert photography and Miss J Mackenzie for typing the manuscript. 
1 Will RG, Matthews WB. A retrospective study of Creutzfeldt-Jakob disease in England and Wales 1970-79 I: Clinical features. $f$ Neurol Neurosurg Psychiatry 1984;47:134-40.

2 Harrison PJ, Roberts GW. "Life, Jim, but not as we know it"? Transmissible dementias and the prion protein. $\mathrm{Br} F$ Psychiatr 1991;158:457-70.

3 Manuelidis EE. Presidential Address: Creutzfeldt-Jakob disease. I Neuropathol Experimental Neurol 1985;44: $1-17$.

4 Hansen LA, Masliah M, Terry RD, Mirra SS. A neuropathological subset of Alzheimer's disease with concomitant Lewy body disease and spongiform change. comitant Lewy body disease and

5 Prusiner SB. Molecular biology of prion diseases. Science 1991;252:1515-22.

6 Penar PL, Prichard JW. Jakob-Creutzfeldt disease associated with cadaveric dura. $\mathcal{F}$ Neurosurg 1987;67:149.

7 Buchanan CR, Preece MA, Milner RDG. Mortality, neoplasia, and Creutzfeldt-Jakob disease in patients treated with human pituitary growth hormone in the United Kingdom. BMF 1991;302:824-8.

8 Prusiner SB. Prions and neurodegenerative diseases. $N$ Engl f Med 1987;317:1571-81

9 Collinge J, Owen F, Poulter M, Leach M, Crow TJ, Rossor MN, Hardy J, Mullan MJ, Janota I, Lantos PL Prion dementia without characteristic pathology. Lancet Prion dementia

10 Will RG. The spongiform encephalopathies. $f$ Neurol Neurosurg Psychiatry 1991;54:761-3.

11 Bell JE, Ironside JW. Department of Health National Surveillance of Creutzfeldt-Jakob Disease. Bull $R$ Coll
Pathol 1991;74:9-10

12 Gajdusek DC, Gibbs CJ Jr, Ashser DM, et al. Precautions in medical care of, and in handling materials from, patients with transmissible virus dementia (CreutzfeldtJakob disease). N Engl ₹ Med 1977;297:1253-8.

13 Traub RD, Gajdusek DC, Gibbs CJ Jr. Precautions in autopsies on Creutzfeldt-Jakob disease. Am $\mathfrak{f}$ Clin Pathol $1975 ; 64: 287$.

14 American Neurological Association. Committee on Health Care Issues. Precautions in handling tissues, fluids, and other contaminated materials from patients with documented or suspected Creutzfeld-Jakob diswith documented or suspected

15 Taylor, DM. Phenolized formalin may not inactivate Creutzfeldt-Jakob disease infectivity. Neuropathol Appl Neurobiol 1989;15:585-6.

16 ACDP. Categorisation of pathogens according to hazard and categories of containment. Appendix J, 2nd Edn 1990:50.

17 Brown P, Wolff A, Gajdusek DC. A simple and effective method for inactivating virus infectivity in formalinfixed tissue samples from patients with CreutzfeldtJakob disease. Neurology 1990;40:887-90.

18 MacArthur $S$, Jacobson $R$, Marrero $H$ et al. Autopsy removal of the brain in AIDS: a new technique. Hum Pathol 1986;17:1296-7.

19 Anonymous editorial. BSE and scrapie: agents for change. Lancet 1988;ii:607-8.

20 Miller DC. Creutzfeldt-Jakob disease in histopathology technicians. N Engl I Med 1988;318:853-4.

21 Gorman DG, Benson DF, Vogel DG, Vinters HV. Creutzfeldt-Jakob disease in a pathologist. Neurology 1992;42:463. 